\title{
Cardiac Biomarkers and Noninvasive Predictors of Atherosclerosis in Chronic Peritoneal Dialysis Patients
}

\author{
Yasar Caliskan ${ }^{a} \quad$ Abdullah Ozkok ${ }^{a}$ Tulin Akagun ${ }^{a}$ Nadir Alpay ${ }^{a}$ Goksel Guz \\ Nihat Polat ${ }^{c}$ Fatih Tufan $^{\mathrm{b}}$ Tevfik Ecder $^{\mathrm{a}}$ Semra Bozfakioglu ${ }^{\mathrm{a}}$ \\ Divisions of a Nephrology and ${ }^{b}$ Geriatrics, Department of Internal Medicine, and ${ }^{\mathrm{C}}$ Department of Cardiology, \\ Istanbul Faculty of Medicine, Istanbul University, Istanbul, Turkey
}

\section{Key Words}

Arterial stiffness $\cdot$ Atherosclerosis $\cdot$ Coronary flow reserve $\cdot$ Intima-media thickness $\cdot$ Peritoneal dialysis $\cdot$ Troponin $T$. Uric acid

\begin{abstract}
Background: We investigated the relationship among serum cardiac biomarkers including $\mathrm{N}$-terminal pro-brain natriuretic peptide (NT-pro-BNP), cardiac troponin T (cTnT), uric acid and high-sensitive C-reactive protein (hs-CRP) and noninvasive predictors of atherosclerosis including carotid intima-media thickness (IMT), aortic stiffness (pulse wave velocity (PWV)) and transthoracic coronary flow reserve (CFR) in peritoneal dialysis (PD) patients. Methods: 37 PD patients were included in the study. We measured (1) carotid IMT, (2) PWV and augmentation index (AIx), and (3) CFR. Simultaneous measurements of serum NT-pro-BNP, cTnT, uric acid and hs-CRP were also performed. Associations among these variables were analyzed. Results: CTnT was significantly associated with carotid IMT $(r=0.747, p<0.001)$, PWV $(r=0.431$, $p=0.035)$ and CFR $(r=-0.439, p=0.007)$. In multivariate analysis, cTnT was a significant independent predictor of carotid IMT $(\beta=4.446, p<0.001)$ and CFR $(\beta=-2.272, p=$
\end{abstract}

0.013). Patients with high cTnT levels ( $\geq 0.01 \mathrm{ng} / \mathrm{ml})$ significantly had higher carotid IMT and PWV values. Only the aortic PWV significantly correlated with residual renal function $(r=-0.574, p=0.004)$. Conclusions: Serum cTnT appeared to be a useful clinical biomarker for evaluating noninvasive predictors of atherosclerosis in chronic PD patients. Arterial stiffness as determined by PWV is also correlated with residual renal function.

Copyright $\odot 2012$ S. Karger AG, Basel

\section{Introduction}

Cardiovascular $(\mathrm{CV})$ disease is the main cause of death during peritoneal dialysis (PD) practice. In dialysis patients, CV complications, such as endothelial dysfunction (ED), vascular calcification, atherosclerosis, valvular disease and left ventricular hypertrophy (LVH), are the most commonly encountered clinical challenges and the most prevalent reasons for morbidity and mortality [1-5]. Therefore, the identification of $\mathrm{CV}$ disease in this population is an important task for nephrologists. Assessment of CV disease severity depends on either evaluation of arterial wall changes reflected by arterial stiffness and

\section{KARGER}

Fax +4161306 1234

E-Mail karger@karger.ch

www.karger.com (c) 2012 S. Karger AG, Basel

$1420-4096 / 12 / 0355-0340 \$ 38.00 / 0$

Accessible online at:

www.karger.com/kbr
Division of Nephrology, Department of Internal Medicine

Istanbul Faculty of Medicine, Capa/Topkapi

TR-34390 Istanbul (Turkey)

Tel. +90 212414 2000, E-Mail ykcaliskan@yahoo.com 
carotid intima-media thickness (IMT) or determination of the functional significance of the stenosis by measurement of its effect on coronary blood flow.

Coronary flow reserve (CFR) represents the capacity of the coronary dilatation following an increase in myocardial metabolic demands [6]. By using this method, early coronary microvasculature pathology and ED can be investigated $[6,7]$. Decreased CFR values $(C F R<2)$ reflect coronary ED and may be evidence of severe coronary artery disease [6-9]. In our previous study, we have also demonstrated that impaired CFR was significant in PD patients [10]. However, its measurement requires specialized medical staff and dedicated echocardiographic equipment, which is not readily available in every hospital. Conversely, IMT and arterial stiffness as measured by pulse wave velocity (PWV) are easier to obtain and do not require prolonged training.

Cardiac biomarkers have also been most extensively evaluated in assessment of CV disease. These biomarkers may reflect left ventricular structure and function and predict outcomes; there has been an escalating interest in the measurement of such biomarkers in asymptomatic end-stage renal disease (ESRD) patients to stratify CV risk [11]. Recent studies suggested that $\mathrm{B}$-type natriuretic peptide (BNP) NT-pro-BNP, C-reactive protein (CRP) and cardiac troponin $\mathrm{T}$ ( $\mathrm{cTn} \mathrm{T}$ ) were predictive of mortality and CV outcomes in both PD and hemodialysis (HD) patients [11-15]. Although CRP and cTnT were confounded by residual kidney function, in previous studies an increased cTnT level was correlated with LVH and systolic dysfunction [11-14]. cTnT was also found as a predictive of mortality and $\mathrm{CV}$ death independent of residual kidney function in dialysis patients [12-15]. On the other hand, hyperuricemia has been linked to CV disease, possibly through the generation of reactive oxygen species and subsequent ED [16]. In a previous study, serum uric acid levels were independently associated with $\mathrm{CV}$ disease including the presence of carotid atherosclerosis and LVH detected by echocardiography [17]. Another biomarker, CRP, was also shown to be significantly related to $\mathrm{LVH}$ and predictive of survival and CV outcomes in PD patients [18].

However, it is not known which biomarkers have the strongest diagnostic potential for atherosclerosis in chronic PD patients. In this cross-sectional study, we investigated the relationship among peritoneal function, residual renal function (RRF), serum cardiac biomarkers and noninvasive predictors of atherosclerosis including carotid IMT, aortic stiffness and transthoracic CFR in PD patients.

Cardiac Biomarkers in Chronic

Peritoneal Dialysis

\section{Methods}

\section{Patients}

A total of 37 adult patients (15 men, 22 women; mean age 48 \pm 14 years, range 1-76) treated for more than 3 months with PD as a renal replacement treatment were included in the study. Information on demography, body mass index (BMI), the etiology of ESRD, duration of PD treatment, CV disease risk factors and cardiac functions were collected by reviewing patient files and medical records. Patients with valvular heart disease, any prior coronary intervention, dilated or hypertrophic cardiomyopathy, congestive heart failure and a history of peritonitis within the last 3 months were excluded. Patients whose left anterior descending coronary artery (LAD) could not be visualized adequately by transthoracic Doppler echocardiography (TTDE) were also excluded. All patients were dialyzed using conventional lactatebuffered glucose-based PD solutions.

Hypertension was defined as systolic blood pressure (BP) $\geq 140 \mathrm{~mm} \mathrm{Hg}$ or diastolic BP $\geq 90 \mathrm{~mm} \mathrm{Hg}$. BP was measured in the sitting position after a 5-min rest with an ERKA sphygmomanometer (PMS Instruments Ltd, Maidenhead, Berks., UK) with an appropriately sized cuff on the right upper arm. BMI was calculated by using the formula of weight $/$ height $^{2}$.

We measured (1) carotid IMT, (2) aortic stiffness-aortic PWV and augmentation index (AIx), and (3) CFR by means of colorguided Doppler echocardiography after dipyridamole infusion. Simultaneous measurements of serum NT-pro-BNP, cTnT, uric acid and high-sensitive CRP (hs-CRP) were also performed. Associations among these variables were analyzed.

Examinations of the patients conformed to good medical and laboratory practices and the recommendations of the Declaration of Helsinki on biomedical research involving human subjects. This study was approved by Ethical Committee of Istanbul Faculty of Medicine.

\section{Laboratory Data}

Fasting serum samples for biochemical studies were obtained between 09:00 and 09:30 h after the first daytime exchange in all cases. Most laboratory values including complete blood cell counts and serum levels of glucose, creatinine, calcium, phosphorus, total protein, albumin, total, HDL and LDL cholesterol, triglycerides and parathyroid hormone (PTH) were measured by standard enzymatic procedures. Serum samples for measurement of NT-pro-BNP, cTnT, uric acid, and hs-CRP were obtained at the time of echocardiographic examination. Serum NT-pro-BNP was measured using a Roche Diagnostics pro-BNP assay on an Elecsys 2010 analyzer (Roche Diagnostics GmbH, Mannheim, Germany). According to data provided by Roche Diagnostics, the detection limit for this peptide is $5 \mathrm{pg} / \mathrm{ml}$. Serum cTnT was determined using the electrochemiluminescence immunoassay (Elecsys 2010 Analyzer; Roche Diagnostics $\mathrm{GmbH}$ ). The detection limit for cTnT with this assay is $0.01 \mathrm{ng} / \mathrm{ml}$. Serum uric acid and hs-CRP levels were measured by a standard enzymatic procedure and nephelometric method (Dade Behring, Marburg, Germany), respectively.

\section{B-Mode High-Resolution Carotid Doppler Examination}

The carotid artery was evaluated in all subjects using an echocardiographic system equipped with $10-\mathrm{mHz}$ linear transducers (VingMed System Five). The subject was examined in the supine

Kidney Blood Press Res 2012;35:340-348 
position with the neck in slight hyperextension to obtain optimal visualization of the common carotid artery, carotid bifurcation and carotid bulb. A trained sonographer scanned the common carotid arteries, the carotid bulbs and the first $2 \mathrm{~cm}$ of the internal and external carotid arteries, all bilaterally. The sonographer visualized the vessels in multiple planes and focused on the interfaces required for measuring the IMT and areas of focal plaque formation. IMT as defined by Pignoli et al. [19] was determined as the distance from the lumen intima interface to the collagencontaining upper layer of the tunica adventitia (the distance between two echogenic lines separated by a hypoechoic or an anechoic space). A local thickening of the intima $>1 \mathrm{~mm}$ in thickness was defined as a plaque. IMT measurements were performed at a distance of $20 \mathrm{~mm}$ from the bifurcation in a plaque-free area of the common carotid. Measurements were done 3-4 times on both right and left sides, and the mean of these measurements was calculated and used. The intra-observer variability for IMT measurements was $4.2 \%$ and the absolute difference between duplicate IMT measurements was $0.03 \mathrm{~mm}$. The degree of carotid artery stenosis was measured at four different sites (communis, bulbus, interna and externa) bilaterally. All measurements were recorded on VHS videotape for subsequent off-line analysis.

\section{Arterial Stiffness}

Arterial stiffness was assessed using the Arteriograph device (TensioMed, Budapest, Hungary) to measure PWV and AIx [20]. The principle of the oscillometric method is based on plethysmography and registers pulsatile pressure changes in an artery. Since fluctuations in pulsatile pressure in the artery beneath the inflated pressure cuff induce periodic pressure changes in the inflated cuff, the oscillometric method measures these periodic pressure changes (oscillations) as an indirect measure for the pulsatile pressure changes in the artery beneath. Consonant with this principle, the Arteriograph initially measures the BP in the upper arm oscillometrically and afterwards produces a cuff pressure over the brachial artery that is $35 \mathrm{~mm} \mathrm{Hg}$ in excess of the systolic $\mathrm{BP}$ measured. The pressure fluctuations in the brachial artery are now detected by the cuff. They are passed on to the computer and recorded and analyzed as pulse waves. The difference in time between the beginning of the first wave and the beginning of the second (reflected) wave is related to the distance from the jugulum to the symphysis, resulting in the PWV in $\mathrm{m} / \mathrm{s}$. Higher values of PWV represent stiffer vessels. The software of the Arteriograph decomposes the early, late systolic and diastolic waves and also determines the onset and the peaks of the waves. For PWV analysis, the onsets of the waves are determined by using first and second derivatives. In a technical stratagem, to intensify the signal and thus attain better differentiation of the initial wave from the reflective wave, the Arteriograph only records and analyses the pulse waves when a suprasystolic pressure of $35 \mathrm{~mm} \mathrm{Hg}$ has been attained. The AIx corresponds to the pressure difference (amplitude difference; P1 - P2) between the first and second wave in relation to the pulse pressure (PP). The Arteriograph calculates the AIx on the basis of the formula AIx $\%=[(\mathrm{P} 2-\mathrm{P} 1) / \mathrm{PP}] \times 100$, and thus provides the brachial AIx without applying a transfer function.

\section{Coronary Flow Measurement}

All of the measurements were performed between 09:00 and 10:00 $\mathrm{h}$ and all of the subjects abstained from caffeine-containing drinks for at least $12 \mathrm{~h}$ before testing. A single investigator, experienced in this data acquisition, performed the CFR recordings, which were performed by the Vivid 7 echocardiography device (General Electrics, Waukesha, Wisc., USA) using a middle range frequency $(3-8 \mathrm{MHz})$ broadband transducer.

The CFR recordings were performed in the LAD by TTDE, as previously described [7]. The acoustic window was around the midclavicular line in the fourth and fifth intercostal spaces in the left lateral decubitus position. The left ventricle was imaged in the long-axis cross section and the ultrasound beam was inclined laterally. The coronary blood in the mid-to-distal LAD was searched by color Doppler flow mapping guidance with the optimal velocity range $(+12$ to $+15 \mathrm{~cm} / \mathrm{s})$. The sample volume $(1.5$ or $2.0 \mathrm{~mm}$ wide) was then positioned on the color signal in the LAD. Variables of LAD velocity were measured by using fast Fourier transformation analysis. After baseline recordings of flows, dipyridamole (Persantin, $0.56 \mathrm{mg} / \mathrm{kg}$; Boehringer Ingelheim, Barcelona, Spain) was infused over a 4 -min period. An additional infusion of dipyridamole $(0.28 \mathrm{mg} / \mathrm{kg}$ over a 2 -min period) was used if the heart rate did not exceed a $10 \%$ increase from the baseline. Two minutes after the end of the infusion, hyperemic spectral profiles in the LAD were recorded. All images were recorded for playback analysis and were later measured off-line. Average diastolic peak flow velocity (ADPV) and average mean diastolic flow velocity were measured at baseline and under hyperemic conditions. CFR was defined as the ratio of ADPV at hyperemia/ADPV at baseline. The intra-observer variability of CFR measurement was 3.6\% in the current study. CFR $<2.0$ was considered abnormal [8-10].

\section{Assessment of RRF and Dialysis Indices}

Residual glomerular filtration rate was measured as the average of 24-hour urine urea and creatinine clearance [21]. Adequacy of dialysis was estimated by measuring total weekly Kt/V urea and creatinine clearance using standard methods [22].

\section{Statistical Analysis}

The statistical analysis was carried out by Statistical Package for Social Sciences for Windows, version 15.0 (SPSS Inc., Chicago, Ill., USA). Numerical variables were given as mean $\pm S D$, and were compared by independent samples t test. When distribution was abnormal, nonparametric tests were used. Relationships were determined with Pearson's correlation coefficient. Correlations between numerical parameters were analyzed by Spearman's $\rho$ correlation test. $\mathrm{p}<0.05$ was accepted as significant.

\section{Results}

\section{Patients}

The baseline characteristics of the patients are shown in table 1 . Time spent on PD was $58 \pm 39$ (range 3-168) months. 22 (59.5\%) patients were treated by continuous ambulatory peritoneal dialysis (CAPD) and the remaining $(\mathrm{n}=15,40.5 \%)$ by continuous cyclic peritoneal dialysis (CCPD). Patients treated by CAPD were older than the patients on CCPD treatment $(52 \pm 13$ vs. $42 \pm 14$ years, $\mathrm{p}=0.04)$. When the results were analyzed according to 


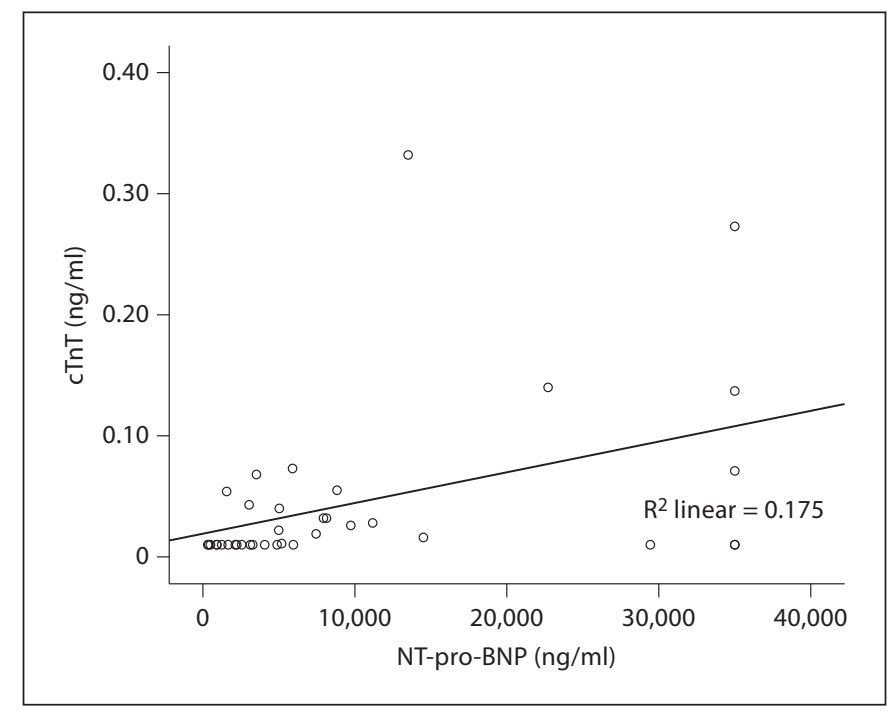

Fig. 1. Correlation between cTnT levels and NT-pro-BNP $(\mathrm{r}=$ $0.418, \mathrm{p}=0.01$ ).

PD modality, there were no differences considering gender, BMI, baseline heart rate and mean arterial pressure. Serum levels of glucose, creatinine, uric acid, calcium, phosphorus, albumin, total, HDL and LDL cholesterol, and triglyceride were similar between the patients on CAPD and CCPD treatments. Serum NT-pro-BNP, cTnT and hs-CRP levels were also similar between the two groups. Peritoneal transport characteristics were as follows: high $(\mathrm{n}=7)$, high average $(\mathrm{n}=19)$ and low average $(\mathrm{n}=11)$.

Overall, mean serum uric acid, NT-pro-BNP, cTnT and hs-CRP of the patients were $4.79 \pm 0.78 \mathrm{mg} / \mathrm{dl}$, $10,047 \pm 11,670 \mathrm{ng} / \mathrm{ml}, 0.04 \pm 0.07 \mathrm{ng} / \mathrm{ml}$ and $8.13 \pm$ $8.50 \mathrm{mg} / \mathrm{l}$, respectively (table 1). There were no significant differences in serum cardiac biomarker levels with regard to gender, etiology of ESRD and PD treatment groups. The serum levels of cardiac biomarkers did not differ among the three transport groups either.

Serum levels of cardiac biomarkers were not correlated with time on $\mathrm{PD}$, mean arterial pressure, glucose, creatinine, calcium, phosphorus, albumin, total, HDL and LDL cholesterol, PTH and hemoglobin levels. Serum uric acid levels were strongly correlated with triglyceride levels $(r=0.548, \mathrm{p}<0.001)$ and BMI $(r=0.426$, $\mathrm{p}=0.009)$. Among the cardiac biomarkers, only cTnT levels correlated with NT-pro-BNP levels $(\mathrm{r}=0.418, \mathrm{p}=$ 0.01 ) (fig. 1). There was also a positive correlation between serum NT-pro-BNP levels and BMI values $(\mathrm{r}=$ $-0.466, \mathrm{p}=0.004)$. Both $\mathrm{cTnT}$ and hs-CRP levels were
Table 1. Demographic, clinical and biochemical features of the patients

Patients on PD $(\mathrm{n}=37)$

\begin{tabular}{lc} 
Age, years & $48 \pm 14(21-76)$ \\
Gender, male/female & $15 / 22$ \\
BMI & $24.5 \pm 4.3(15.9-35.8)$ \\
Time on dialysis, months & $58 \pm 39(3-168)$ \\
Mean arterial pressure, mm Hg & $92 \pm 16(60-120)$ \\
\hline Etiology of ESRD & \\
Glomerulonephritis & $15(40.5 \%)$ \\
Interstitial nephritis & $7(18.9 \%)$ \\
Diabetic nephropathy & $5(13.5 \%)$ \\
Hypertensive nephrosclerosis & $3(8.1 \%)$ \\
Polycystic kidney disease & $3(8.1 \%)$ \\
Amyloidosis & $1(2.7 \%)$ \\
Unknown & $3(8.1 \%)$ \\
\hline Laboratory data & \\
Glucose, mg/dl & $103 \pm 39(53-284)$ \\
Creatinine, mg/dl & $8.9 \pm 2.1(4.9-14.2)$ \\
Calcium, mg/dl & $8.99 \pm 0.98(6.50-10.70)$ \\
Phosphorus, mg/dl & $3.00 \pm 7.80(5.26-1.17)$ \\
Albumin, g/dl & $3.80 \pm 0.30(3.1-4.4)$ \\
Total cholesterol, mg/dl & $188 \pm 38(115-277)$ \\
HDL cholesterol, mg/dl & $43 \pm 15(23-83)$ \\
LDL cholesterol, mg/dl & $113 \pm 36(39-181)$ \\
Triglyceride, mg/dl & $160 \pm 89(66-544)$ \\
PTH, pg/ml & $448 \pm 504(34-2,319)$ \\
Hemoglobin, g/dl & $10.6 \pm 1.5(7.5-13.1)$ \\
Uric acid, mg/dl & $4.79 \pm 0.78(3.20-6.50)$ \\
hs-CRP, mg/l & $8.13 \pm 8.50(0.94-34.76)$ \\
NT-pro-BNP, ng/ml & $0.04 \pm 0.07(0.01-0.33)$ \\
cTnT, ng/ml & $2.24 \pm 0.34(1.66-3.15)$ \\
Total weekly Kt/V urea & $61.7 \pm 16.4(32.4-105.1)$ \\
Total weekly creatinine clearance & \\
&
\end{tabular}

correlated with age $(\mathrm{r}=0.439, \mathrm{p}=0.007$ and $\mathrm{r}=0.386$, $\mathrm{p}=0.018$, respectively).

\section{Cardiac Biomarkers}

cTnT was significantly associated with carotid IMT $(\mathrm{r}=0.747, \mathrm{p}<0.001)$, arterial stiffness (PWV; $\mathrm{r}=0.431$, $\mathrm{p}=0.035)$ and CFR $(\mathrm{r}=-0.439, \mathrm{p}=0.007)$. Serum uric acid, hs-CRP and NT-pro-BNP were not found to be associated with noninvasive predictors of atherosclerosis including carotid IMT, aortic stiffness and transthoracic CFR in PD patients (table 2). In multivariate analysis, cTnT was a significant independent predictor of carotid IMT $(\beta=4.446, p<0.001)$ and CFR $(\beta=-2.272, p=$ $0.013)$ in PD patients. When the patients were divided into two groups according to their cTnT levels (first group, normal cTnT levels $(<0.01 \mathrm{ng} / \mathrm{ml})$; second group, 
Table 2. Correlation analysis between noninvasive predictors of atherosclerosis and cardiac biomarkers

\begin{tabular}{|c|c|c|c|c|c|c|}
\hline \multirow[t]{2}{*}{ Cardiac biomarkers } & \multicolumn{2}{|c|}{ Carotid IMT } & \multicolumn{2}{|c|}{$\begin{array}{l}\text { Arterial stiffness } \\
(\mathrm{PWV})\end{array}$} & \multicolumn{2}{|l|}{ CFR } \\
\hline & $\mathrm{r}$ & $\mathrm{p}$ value & $\mathrm{r}$ & $\mathrm{p}$ value & $\mathrm{r}$ & $\mathrm{p}$ value \\
\hline Uric acid, mg/dl & -0.27 & 0.11 & -0.26 & 0.23 & 0.17 & 0.31 \\
\hline hs-CRP, mg/l & 0.31 & 0.06 & 0.08 & 0.71 & 0.02 & 0.93 \\
\hline NT-pro-BNP, ng/ml & 0.29 & 0.08 & 0.28 & 0.19 & -0.11 & 0.52 \\
\hline cTnT, ng/dl & 0.75 & $<0.001$ & 0.43 & 0.03 & -0.44 & 0.007 \\
\hline
\end{tabular}

high cTnT levels ( $\geq 0.01 \mathrm{ng} / \mathrm{ml})$ ), it was seen that patients in the second group significantly had higher carotid IMT and PWV values (table 3 ).

\section{Carotid IMT Measurements}

The mean carotid IMT of the patients was $0.85 \pm 0.43$ $\mathrm{mm}$. Carotid artery plaque was positive in $5 / 37$ (13.5\%) of the patients. Serum cTnT $(0.14 \pm 0.12$ vs. $0.03 \pm 0.05 \mathrm{ng} /$ $\mathrm{ml}, \mathrm{p}=0.001)$ and NT-pro-BNP $(24,146 \pm 10,533$ vs. $7,844 \pm 10,332 \mathrm{ng} / \mathrm{ml}, \mathrm{p}=0.002)$ levels were significantly higher in patients with carotid artery plaque than the remaining group. The correlation analysis between carotid IMT and different laboratory variables including cardiac biomarkers revealed that carotid IMT was significantly correlated with cTnT levels $(\mathrm{r}=0.747, \mathrm{p}<0.001)$ (fig. 2a). Carotid IMT levels were also significantly correlated with PWV $(\mathrm{r}=0.431, \mathrm{p}=0.036)$.

\section{Arterial Stiffness Measurements}

The mean aortic PWV of the patients was $10.55 \pm 2.72$ $\mathrm{m} / \mathrm{s}$ (range 5.70-14.90). The mean AIx was $34.47 \pm 21.54$ $\mathrm{m} / \mathrm{s}$ (range 1.50-73.00). The correlation analysis between PWV and different laboratory variables including cardiac biomarkers revealed that PWV was significantly correlated with $c \operatorname{TnT}$ levels $(\mathrm{r}=0.431, \mathrm{p}=0.035)$ (fig. $2 b)$. Aortic PWV was also significantly correlated with RRF $(\mathrm{r}=-0.574, \mathrm{p}=0.004)$ (fig. 3).

\section{Coronary Flow Measurements}

On TTDE examination, the mean CFR level was 1.75 \pm 0.35 . There were no significant differences in CFR values of patients with regard to gender, etiology of ESRD, PD treatment arm, peritoneal transport type and presence of RRF. Since a CFR value $<2$ was accepted as an evidence of coronary artery disease, patients with impaired CFR values $(78 \%)$ were significantly common in the PD study group. Patients were divided into two groups whether they had lower $(\mathrm{CFR}<2 ; \mathrm{n}=29)$ or higher $(\mathrm{CFR}$
Table 3. Demographic features, biochemical and cardiac test results of the patients characterized by lower or higher cTnT values

\begin{tabular}{|c|c|c|c|}
\hline & $\begin{array}{l}\mathrm{cTnT} \\
<0.01 \mathrm{ng} / \mathrm{ml} \\
(\mathrm{n}=18)\end{array}$ & $\begin{array}{l}\mathrm{cTnT} \\
\geq 0.01 \mathrm{ng} / \mathrm{ml} \\
(\mathrm{n}=19)\end{array}$ & $\begin{array}{l}\mathrm{p} \\
\text { value }\end{array}$ \\
\hline Age, years & $42 \pm 13$ & $54 \pm 13$ & 0.007 \\
\hline Gender, male/female & $7 / 11$ & $8 / 11$ & 0.84 \\
\hline BMI & $23.7 \pm 4.1$ & $25.2 \pm 4.4$ & 0.26 \\
\hline Time on dialysis, months & $52 \pm 40$ & $64 \pm 38$ & 0.38 \\
\hline $\begin{array}{l}\text { Mean arterial pressure, } \\
\text { mm Hg }\end{array}$ & $87 \pm 16$ & $96 \pm 15$ & 0.06 \\
\hline \multicolumn{4}{|l|}{ Laboratory data } \\
\hline Glucose, mg/dl & $90 \pm 16$ & $113 \pm 50$ & 0.07 \\
\hline Creatinine, $\mathrm{mg} / \mathrm{dl}$ & $9.6 \pm 2.1$ & $8.3 \pm 1.9$ & 0.05 \\
\hline Calcium, mg/dl & $9.1 \pm 1.1$ & $8.9 \pm 0.9$ & 0.71 \\
\hline Phosphorus, mg/dl & $5.2 \pm 1.0$ & $5.3 \pm 1.4$ & 0.78 \\
\hline Albumin, g/dl & $3.76 \pm 0.29$ & $3.76 \pm 0.33$ & 0.94 \\
\hline Total cholesterol, mg/dl & $189 \pm 33$ & $187 \pm 43$ & 0.90 \\
\hline HDL cholesterol, mg/dl & $43 \pm 17$ & $43 \pm 13$ & 0.89 \\
\hline LDL cholesterol, mg/dl & $113 \pm 35$ & $113 \pm 37$ & 0.99 \\
\hline Triglyceride, $\mathrm{mg} / \mathrm{dl}$ & $180 \pm 112$ & $141 \pm 55$ & 0.18 \\
\hline $\mathrm{PTH}, \mathrm{pg} / \mathrm{ml}$ & $467 \pm 578$ & $432 \pm 442$ & 0.84 \\
\hline Hemoglobin, g/dl & $10.5 \pm 1.6$ & $10.7 \pm 1.4$ & 0.60 \\
\hline Total weekly Kt/V urea & $2.21 \pm 0.37$ & $2.27 \pm 0.32$ & 0.60 \\
\hline \multicolumn{4}{|l|}{ Cardiac biomarkers } \\
\hline Uric acid, mg/dl & $5.33 \pm 1.23$ & $4.98 \pm 0.90$ & 0.33 \\
\hline hs-CRP, mg/l & $8.05 \pm 8.46$ & $8.20 \pm 8.77$ & 0.96 \\
\hline NT-pro-BNP, ng/ml & $7,419 \pm 11,992$ & $12,536 \pm 11,094$ & 0.19 \\
\hline \multicolumn{4}{|l|}{ Noninvasive cardiac tests } \\
\hline Carotid IMT, mm & $0.65 \pm 0.16$ & $1.03 \pm 0.52$ & 0.006 \\
\hline $\mathrm{PWV}, \mathrm{m} / \mathrm{s}$ & $9.36 \pm 2.41$ & $11.56 \pm 2.64$ & 0.04 \\
\hline CFR & $1.82 \pm 0.33$ & $1.68 \pm 0.36$ & 0.24 \\
\hline $\mathrm{EF}, \%$ & $61 \pm 11$ & $58 \pm 11$ & 0.47 \\
\hline
\end{tabular}

$\geq 2 ; n=8$ ) CFR values (table 4). The only statistically significant difference between the two subgroups was that serum PWV levels in patients with CFR $<2(11.23 \pm 2.41$ $\mathrm{m} / \mathrm{s}$ ) were significantly higher than the patients with CFR $\geq 2(8.53 \pm 2.80 \mathrm{~m} / \mathrm{s})(\mathrm{p}=0.032)($ table 4$)$. The correlation 

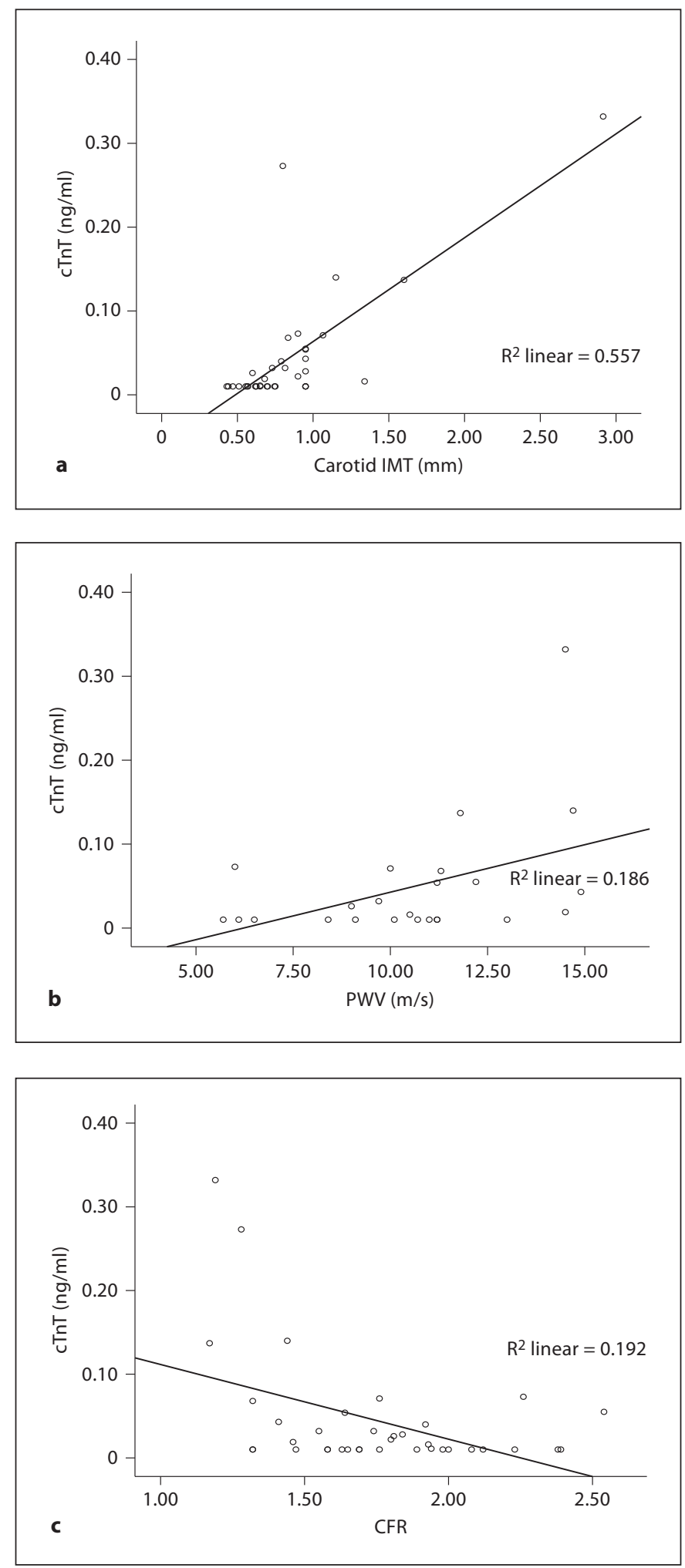

Fig. 2. a Correlation between cTnT levels and carotid IMT ( $\mathrm{r}=$ $0.747, \mathrm{p}<0.001)$. b Correlation between cTnT levels and arterial stiffness measured by PWV $(\mathrm{r}=0.431, \mathrm{p}=0.035)$. c Correlation between cTnT levels and CFR $(\mathrm{r}=-0.439, \mathrm{p}=0.007)$.

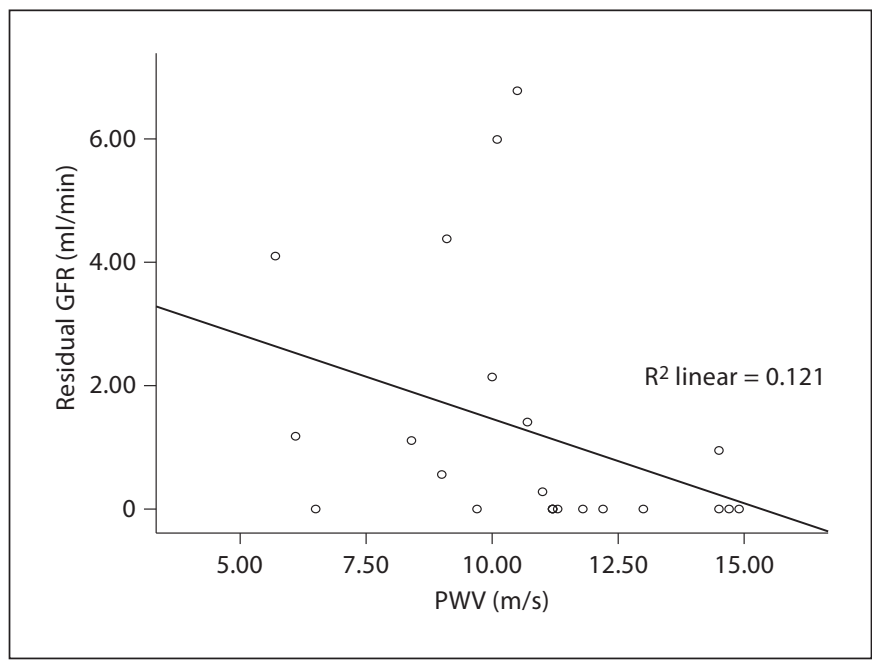

Fig. 3. Arterial stiffness measured by aortic PWV was inversely correlated with RRF $(r=-0.574, \mathrm{p}=0.004)$.

Table 4. Demographic features, biochemical and cardiac test results of the patients characterized by lower or higher CFR values

\begin{tabular}{|c|c|c|c|}
\hline & $\begin{array}{l}\text { CFR }<2 \\
(n=29)\end{array}$ & $\begin{array}{l}\mathrm{CFR} \geq 2 \\
(\mathrm{n}=8)\end{array}$ & $\begin{array}{l}\mathrm{p} \\
\text { value }\end{array}$ \\
\hline Age, years & $48 \pm 15$ & $46 \pm 10$ & 0.72 \\
\hline Gender, male/female & $11 / 18$ & $4 / 4$ & 0.54 \\
\hline BMI & $24.1 \pm 4.3$ & $25.9 \pm 4.1$ & 0.62 \\
\hline Time on dialysis, months & $59 \pm 40$ & $54 \pm 37$ & 0.77 \\
\hline $\begin{array}{l}\text { Mean arterial pressure, } \\
\text { mm Hg }\end{array}$ & $91 \pm 17$ & $96 \pm 12$ & 0.43 \\
\hline \multicolumn{4}{|l|}{ Laboratory data } \\
\hline Glucose, mg/dl & $104 \pm 43$ & $95 \pm 20$ & 0.58 \\
\hline Creatinine, $\mathrm{mg} / \mathrm{dl}$ & $9.0 \pm 2.1$ & $8.8 \pm 2.1$ & 0.77 \\
\hline Calcium, mg/dl & $9.1 \pm 0.9$ & $8.7 \pm 1.2$ & 0.36 \\
\hline Phosphorus, mg/dl & $5.3 \pm 1.1$ & $5.1 \pm 1.4$ & 0.61 \\
\hline Albumin, g/dl & $3.76 \pm 0.32$ & $3.75 \pm 0.28$ & 0.92 \\
\hline Total cholesterol, mg/dl & $187 \pm 41$ & $193 \pm 24$ & 0.67 \\
\hline HDL cholesterol, mg/dl & $45 \pm 15$ & $35 \pm 8$ & 0.07 \\
\hline LDL cholesterol, mg/dl & $109 \pm 38$ & $127 \pm 25$ & 0.22 \\
\hline Triglyceride, mg/dl & $163 \pm 98$ & $151 \pm 42$ & 0.74 \\
\hline $\mathrm{PTH}, \mathrm{pg} / \mathrm{ml}$ & $472 \pm 525$ & $347 \pm 422$ & 0.56 \\
\hline Hemoglobin, g/dl & $10.8 \pm 1.1$ & $10.0 \pm 2.3$ & 0.22 \\
\hline Total weekly Kt/V urea & $2.22 \pm 0.36$ & $2.33 \pm 0.26$ & 0.43 \\
\hline \multicolumn{4}{|l|}{ Cardiac biomarkers } \\
\hline Uric acid, mg/dl & $5.08 \pm 1.15$ & $5.40 \pm 0.76$ & 0.47 \\
\hline hs-CRP, mg/l & $7.87 \pm 9.12$ & $9.06 \pm 6.09$ & 0.73 \\
\hline NT-pro-BNP, ng/ml & $10,794 \pm 11,803$ & $7,338 \pm 11,507$ & 0.47 \\
\hline cTnT, ng/ml & $0.05 \pm 0.08$ & $0.02 \pm 0.03$ & 0.35 \\
\hline \multicolumn{4}{|l|}{ Noninvasive cardiac tests } \\
\hline Carotid IMT, mm & $0.88 \pm 0.47$ & $0.73 \pm 0.19$ & 0.39 \\
\hline $\mathrm{PWV}, \mathrm{m} / \mathrm{s}$ & $11.22 \pm 2.41$ & $8.53 \pm 2.80$ & 0.03 \\
\hline $\mathrm{EF}, \%$ & $58 \pm 11$ & $64 \pm 7$ & 0.23 \\
\hline
\end{tabular}


analysis between CFR and different laboratory variables including cardiac biomarkers revealed that CFR was significantly correlated with cTnT levels $(\mathrm{r}=-0.439, \mathrm{p}=$ 0.007 ) (fig. 2c). When the correlation analysis among CFR, carotid IMT and arterial stiffness was performed, CFR values were significantly correlated with carotid $\operatorname{IMT}(\mathrm{r}=-0.313, \mathrm{p}=0.05)$ and PWV $(\mathrm{r}=-0.538, \mathrm{p}=$ $0.007)$.

\section{Ejection Fraction}

On echocardiographic examination, the mean ejection fraction $(\mathrm{EF})$ level was $59.5 \pm 10.9 \%$. There were no significant differences in EF values of patients with regard to gender, etiology of ESRD, PD treatment arm, peritoneal transport type and presence of RRF. Among the cardiac biomarkers, hs-CRP $(\mathrm{r}=-0.510, \mathrm{p}=0.002)$, NTpro-BNP $(\mathrm{r}=-0.656, \mathrm{p}<0.001)$ and $\mathrm{cTnT}(\mathrm{r}=-0.370$, $\mathrm{p}=0.034$ ) levels were inversely correlated with EF values. EF was also correlated with CFR values $(r=0.370$, $\mathrm{p}=0.034)$. In the multiple linear regression analyses, EF was independently associated with serum hs-CRP ( $\beta=$ $-0.399, \mathrm{p}=0.002)$ and NT-pro-BNP $(\beta=-0.538, \mathrm{p}<$ $0.001)$, but not with serum uric acid and cTnT.

\section{Discussion}

In the present study, serum cTnT levels corresponded closely to noninvasive predictors of atherosclerosis including carotid IMT, aortic arterial stiffness and CFR measured by TTDE during pharmacological coronary vasodilatation. The serum cTnT level was found as a significant independent predictor of carotid IMT and CFR in PD patients. To our knowledge, this is the first study to show that the assessment of cardiac biomarkers correlates with the functional significance of atherosclerosis measured by carotid IMT, arterial stiffness and CFR. Furthermore, we have also shown that arterial stiffness as determined by PWV is correlated with RRF.

The CFR measurement which reflects coronary microvascular function and endothelial functions of epicardial coronary arteries by TTDE, as a cheaper and easy screening test, may be used as a detection method in the assessment of major epicardial coronary arteries [7-10]. Impairment of the CFR $(\mathrm{CFR}<2)$ has been suggested to be a preclinical sign of $\mathrm{CV}$ events and is characterized by a decreased capacity of the coronary dilatation following an increase in myocardial metabolic demands [7-10]. In this study, decreased CFR values were noted in 29 of 37 (78\%) patients. Many well-defined CV risk factors may be present in individuals who require dialysis and contribute to this high frequency of CFR impairment. Another noninvasive test, arterial stiffness measurement (PWV), was shown to be associated with coronary atherosclerosis assessed by angiography in the previous reports [23, 24]. This association was also shown in the ESRD population [25]. Although the accuracy of cardiac biomarkers in evaluating CV disease is improving, the relation between cardiac biomarkers and anatomical and functional assessment of atherosclerosis remains unclear. Therefore, we planned to examine the correlation between cardiac biomarkers and noninvasive predictors of atherosclerosis including CFR, carotid IMT and arterial stiffness by simultaneously performing these tests in a cross-sectional cohort of PD patients. The main result of our investigation is that there is an association of cardiac biomarkers, especially cTnT with carotid, aortic and coronary atherosclerosis. As the release of cTnT into the circulation occurs with cardiomyocyte injury, cTnT is a preferred marker for diagnosing acute coronary syndrome. However, recent reports suggested that hs-cTnT is an independent predictor for the presence of coronary atherosclerosis also in patients without acute coronary syndrome [26, 27]. Additionally, previous studies in ESRD populations also showed an association of elevated cTnT levels with coronary and carotid atherosclerosis which is compatible with our results $[28,29]$. Traditionally it was thought that the release of cTnT is equivalent to myocardial necrosis; however, some recent animal studies have suggested that short episodes of ischemia may result in the release of cTnT, without demonstration of cell death [30]. These studies also suggested that elevated hs-cTnT levels observed in patients with coronary artery disease may be the result of activation of caspase-3 within cardiac myocytes and the resulting cleavage and release of cTnT, but they do not necessarily implicate myocardial cell death [31-33]. Atherosclerosis-related decreased coronary perfusion may cause the activation of caspase- 3 and release of $c \operatorname{TnT}$ into the circulation. The association between serum cTnT and diffuse atherosclerosis may suggest that cTnT is a marker for the development of atherosclerotic artery disease and could be a powerful cardiac biomarker to assess $\mathrm{CV}$ risk in $\mathrm{PD}$ patients.

In this study, uric acid, hs-CRP, NT-pro-BNP and cTnT were evaluated as cardiac biomarkers. Although serum uric acid, hs-CRP and NT-pro-BNP were not found to be associated with noninvasive predictors of atherosclerosis including carotid IMT, aortic stiffness and transthoracic CFR, cTnT was found as a significant independent predictor of carotid IMT and CFR in PD pa- 
tients. According to previous studies, serum $c \operatorname{TnT}$ and NT-pro-BNP appear to measure different aspects of CV disease [11, 13, 34-36]. Satyan et al. [36] showed an independent correlation of NT-pro-BNP with left ventricular systolic dysfunction in a HD population, while cTnT independently correlated with left ventricular mass index in this study. A recent study by Wang et al. [11] demonstrated that NT-pro-BNP had the highest diagnostic value for severe LVH and systolic dysfunction compared to cTnT and hs-CRP in PD patients. In the present study, NT-pro-BNP, cTnT and hs-CRP levels were inversely correlated with left ventricular EF values. Previous studies have also shown similar findings [11, 34-36]. However, studies evaluating the relationship between $\mathrm{cTnT}$ and left ventricular parameters have yielded conflicting results. Mallamaci et al. $[13,37]$ suggested that $c \operatorname{TnT}$ had a significant correlation with left ventricular mass and left ventricular systolic dysfunction in their cohort of $258 \mathrm{HD}$ patients. DeFilippi et al. [29] found no significant association between cTnT quartiles and LVH in HD patients, but reduced left ventricular EF was twice as frequent among those in the higher cTnT quartiles in comparison with those with lower cTnT quartiles. In a PD population, Wang et al. [11] showed that cTnT may be useful in ruling out severe LVH and systolic dysfunction in PD patients, although the area under curves were slightly lower than that of NT-pro-BNP. In our study, when multiple linear regression analyses were performed, EF was independently associated with serum hs-CRP and NT-pro-BNP, but the correlation between $\mathrm{CTnT}$ and $\mathrm{EF}$ was lost when NT-pro-BNP was included in the multivariate analysis. Although several recent studies have shown the association between serum uric acid levels and atherosclerosis in various patient populations $[38,39]$, uric acid levels were not found to be associated with noninvasive predictors of atherosclerosis and $\mathrm{EF}$ in our PD patients.

An additional unique feature of the present study was the association between carotid IMT, aortic PWV and
CFR in PD patients. Previous studies demonstrated the association of CFR values with PWV and carotid IMT levels in other patient populations [40,41]. The suggested mechanism of this association is that arterial stiffness causes a mismatch between myocardial oxygen demands and myocardial perfusion resulting in subendocardial ischemia, left ventricle diastolic dysfunction and elevation of diastolic filling pressure, which further decreases myocardial perfusion determined by impaired CFR [42]. Although the relation between these three predictors of $\mathrm{CV}$ risk is not clear in $\mathrm{PD}$ population, our results establish a close relationship between increasing arterial stiffness, IMT and reduced CFR values in PD patients.

$\mathrm{RRF}$ is related to all-cause mortality and risk of $\mathrm{CV}$ death in patients on dialysis. Wang et al. [43] demonstrated an association between RRF and LVH in nondiabetic PD patients. Another study by Huang et al. [44] showed an association between arterial stiffness and RRF in a retrospective study of $146 \mathrm{PD}$ patients. A recent study by Han et al. [45] also demonstrated the association of reduced RRF with ED which is an early marker of atherosclerosis. In the present study, arterial stiffness as determined by PWV is the only noninvasive predictor of atherosclerosis that also correlated with reduced RRF. This finding may suggest that RRF may contribute to CV protection in PD patients.

In conclusion, the serum cTnT level was found as a significant independent predictor of carotid IMT and CFR in PD patients. Therefore, serum cTnT appeared to be a useful clinical biomarker for evaluating noninvasive predictors of atherosclerosis in chronic PD patients. The association between carotid IMT, aortic PWV and CFR may suggest that PWV which was also correlated with $\mathrm{RRF}$ is a marker for the development of atherosclerotic coronary artery disease and can be a powerful noninvasive tool to assess CV risk in PD patients.

\section{References}

Cardiac Biomarkers in Chronic

Peritoneal Dialysis
1 United States Renal Data System, USRDS 2010 Annual Data Report: Atlas of EndStage Renal Disease in the United States. Bethesda, National Institute of Health and National Institute of Diabetes and Digestive and Kidney Diseases, 2010.

2 Raine AEG, Margreiter R, Brunner FP, et al: Report on management of renal failure in Europe, XXII, 1991. Nephrol Dial Transplant 1992;7(suppl 2):7-35.
>3 Rostand SG, Kirk KA, Rutsky EA: Dialysisassociated ischemic heart disease: insights from coronary angiography. Kidney Int 1984;225:653-659.

4 Harnett JD, Foley RN, Kent GM, Barre PE, Murray D, Parfrey PS: Congestive heart failure in dialysis patients: prevalence, incidence, prognosis and risk factors. Kidney Int 1995;47:884-890. 
5 Parfrey PS, Foley RN, Harnett JD, Kent GM, 20 Baulmann J, Schillings U, Rickert S, et al: A Murray DC, Barre PE: Outcome and risk factors of ischemic heart disease in chronic uremia. Kidney Int 1996;49:1428-1434.

6 Rigo F: Coronary flow reserve in stress-echo lab. From pathophysiologic toy to diagnostic tool. Cardiovasc Ultrasound 2005;3:8.

$\checkmark 7$ Pizzuto F, Voci P, Mariano E, Puddu PE, Chiavari PA, Romeo F: Noninvasive coronary flow reserve assessed by transthoracic coronary Doppler ultrasound in patients with left anterior descending coronary artery stents. Am J Cardiol 2003;91:522-526.

8 Caliskan Y, Oflaz H, Demirturk M, et al: Coronary flow reserve dysfunction in hemodialysis and kidney transplant patients. Clin Transplant 2008;22:785-793.

$\checkmark$ Lambertz H, Tries HP, Stein T, Lethen H: Noninvasive assessment of coronary flow reserve with transthoracic signal-enhanced Doppler echocardiography. J Am Soc Echocardiogr 1999;12:186-195.

10 Caliskan Y, Gorgulu N, Yelken B, et al: Plasma ghrelin levels are associated with coronary microvascular and endothelial dysfunction in peritoneal dialysis patients. Ren Fail 2009;31:807-813.

11 Wang AY, Lam CW, Wang M, et al: Diagnostic potential of serum biomarkers for left ventricular abnormalities in chronic peritoneal dialysis patients. Nephrol Dial Transplant 2009;24:1962-1969.

12 Wang AY, Lam CW, Wang M, et al: Prognostic value of cardiac troponin $\mathrm{T}$ is independent of inflammation, residual renal function, and cardiac hypertrophy and dysfunction in peritoneal dialysis patients. Clin Chem 2007;53:882-889.

13 Mallamaci F, Zoccali C, Parlongo S, et al: Troponin is related to left ventricular mass and predicts all-cause and cardiovascular mortality in hemodialysis patients. Am J Kidney Dis 2002;40:68-75.

14 Apple FS, Murakami MM, Pearce LA, et al: Predictive value of cardiac troponin I and T for subsequent death in end-stage renal disease. Circulation 2002;106:2941-2945.

$\checkmark 15$ Dierkes J, Domrose U, Westphal S, et al: Cardiac troponin $\mathrm{T}$ predicts mortality in patients with end-stage renal disease. Circulation 2000;102:1964-1969.

16 Khosla UM, Zharikov S, Finch JL, et al: Hyperuricemia induces endothelial dysfunction. Kidney Int 2005;67:1739-1742.

17 Viazzi F, Parodi D, Leoncini G, et al: Serum uric acid and target organ damage in primary hypertension. Hypertension 2005;45:991996.

18 Wang AY, Woo J, Lam CW, et al: Is a single time point C-reactive protein predictive of outcome in peritoneal dialysis patients? J Am Soc Nephrol 2003;14:1871-1879.

$\checkmark 19$ Pignoli P, Tremoli E, Poli A, Oreste P, Paoletti R: Intimal plus medial thickness of the arterial wall: a direct measurement with ultrasound imaging. Circulation 1986;74:13991406. new oscillometric method for assessment of arterial stiffness: comparison with tonometric and piezo-electronic methods. J Hypertens 2008;26:523-528.

-21 Van Olden RW, Krediet RT, Struijk DG, et al: Measurement of residual renal function in patients treated with continuous ambulatory peritoneal dialysis. J Am Soc Nephrol 1996; 7:745-748.

22 Nolph KD, Moore HL, Twardowski ZJ, et al: Cross-sectional assessment of weekly urea and creatinine clearances in patients on continuous ambulatory peritoneal dialysis. ASAIO J 1992;38:M139-M142.

23 Van Popele NM, Mattace-Raso FU, Vliegenthart R, et al: Aortic stiffness is associated with atherosclerosis of the coronary arteries in older adults: the Rotterdam Study. J Hypertens 2006;24:2371-2376.

24 McLeod AL, Uren NG, Wilkinson IB, et al: Non-invasive measures of pulse wave velocity correlate with coronary arterial plaque load in humans. J Hypertens 2004;22:363-368.

25 Covic A, Haydar AA, Bhamra-Ariza P, Gusbeth-Tatomir P, Goldsmith DJ: Aortic pulse wave velocity and arterial wave reflections predict the extent and severity of coronary artery disease in chronic kidney disease patients. J Nephrol 2005;18:388-396.

26 Laufer EM, Mingels AM, Winkens MH, et al: The extent of coronary atherosclerosis is associated with increasing circulating levels of high sensitive cardiac troponin T. Arterioscler Thromb Vasc Biol 2010;30:1269-1275.

27 Saunders JT, Nambi V, de Lemos JA, et al: Cardiac troponin $\mathrm{T}$ measured by a highly sensitive assay predicts coronary heart disease, heart failure, and mortality in the Atherosclerosis Risk in Communities Study. Circulation 2011;123:1367-1376.

28 Hojs R, Ekart R, Hojs Fabjan T, Balon BP, Gorenjak M: Cardiac troponin $\mathrm{T}$ (cTnT) in hemodialysis patients with asymptomatic and symptomatic atherosclerosis. Arch Med Res 2005;36:367-371.

29 DeFilippi C, Wasserman S, Rosanio S, et al: Cardiac troponin $\mathrm{T}$ and C-reactive protein for predicting prognosis, coronary atherosclerosis, and cardiomyopathy in patients undergoing long-term hemodialysis. JAMA 2003;290:353-359.

- 30 Feng YJ, Chen C, Fallon JT, et al: Comparison of cardiac troponin I, creatine kinase$\mathrm{MB}$, and myoglobin for detection of acute ischemic myocardial injury in a swine model. Am J Clin Pathol 1998;110:70-77.

- 31 Kenis H, Zandbergen HR, Petrov A, et al: Annexin A5 uptake in ischemic myocardium: demonstration of reversible phosphatidylserine externalization and feasibility of radionuclide imaging. J Nucl Med 2010;51: 259-267.

32 Hofstra L, Liem IH, Dumont EA, et al: Visualisation of cell death in vivo in patients with acute myocardial infarction. Lancet 2000; 356:209-212.
3 Communal C, Sumandea M, de Tombe P, Narula J, Solaro RJ, Hajjar RJ: Functional consequences of caspase activation in cardiac myocytes. Proc Natl Acad Sci USA 2002; 99:6252-6256.

34 Zoccali C, Mallamaci F, Benedetto FA, et al: Cardiac natriuretic peptides are related to left ventricular mass and function and predict mortality in dialysis patients. J Am Soc Nephrol 2001;12:1508-1515.

35 Madsen LH, Ladefoged S, Corell P, et al: Nterminal pro-brain natriuretic peptide predicts mortality in patients with end-stage renal disease in hemodialysis. Kidney Int 2007; 71:548-554.

- 36 Satyan S, Light RP, Agarwal R: Relationships of $\mathrm{N}$-terminal pro-B-natriuretic peptide and cardiac troponin $\mathrm{T}$ to left ventricular mass and function and mortality in asymptomatic hemodialysis patients. Am J Kidney Dis 2007;50:1009-1019.

37 Mallamaci F, Zoccali C, Parlongo S, et al: Diagnostic value of troponin $\mathrm{T}$ for alterations in left ventricular mass and function in $\mathrm{di}$ alysis patients. Kidney Int 2002;62:18841890.

38 Kaya EB, Yorgun H, Canpolat U, et al: Serum uric acid levels predict the severity and morphology of coronary atherosclerosis detected by multidetector computed tomography. Atherosclerosis 2010;213:178-183.

39 Rodrigues TC, Maahs DM, Johnson RJ, et al: Serum uric acid predicts progression of subclinical coronary atherosclerosis in individuals without renal disease. Diabetes Care 2010;33:2471-2473.

40 Ikonomidis I, Lekakis J, Papadopoulos C, et al: Incremental value of pulse wave velocity in the determination of coronary microcirculatory dysfunction in never-treated patients with essential hypertension. Am J Hypertens 2008;21:806-813.

41 Takiuchi S, Rakugi H, Fujii H, et al: Carotid intima-media thickness is correlated with impairment of coronary flow reserve in hypertensive patients without coronary artery disease. Hypertens Res 2003;26:945-951.

42 Nichols W, O’Rourke M: McDonald's Blood Flow in Arteries: Theoretical, Experimental and Clinical Principles, ed 5. London, Hodder Arnold, 2005, pp 67-93.

43 Wang AY, Wang M, Woo J, et al: A novel association between residual renal function and left ventricular hypertrophy in peritoneal dialysis patients. Kidney Int 2002;62: 639-647.

44 Huang WH, Chen KH, Hsu CW, et al: The residual renal function - one of the factors associated with arterial stiffness in peritoneal dialysis patients. Insight from a retrospective study in 146 peritoneal dialysis patients. Blood Purif 2008;26:133-137.

45 Han SH, Lee SC, Kang EW, et al: Reduced residual renal function is associated with endothelial dysfunction in patients receiving peritoneal dialysis. Perit Dial Int DOI: $10.3747 /$ pdi.2010.00111, E-pub ahead of print. 